\title{
Research on the Definition and Influence of New Production of Ship Industry Index of Energy Efficiency on the Ship Design Process
}

\author{
Wang Ya Tao ${ }^{1, a}$ \\ 1 TianJin Maritime College , \\ TianJin , 300350 China
}

\author{
Wu Fei ${ }^{1, a}$ \\ ${ }^{1}$ TianJin Maritime College , \\ TianJin , 300350 China
}

\begin{abstract}
In this paper, we conduct research on the definition and influence of new production of ship industry index of energy efficiency on the ship design process. Ship energy saving is the key to energy saving ship form optimization design. In the ship under the conditions of use, and to optimize the design of the hull lines with boat, minimize the ship resistance, with the final choice of ship host fuel-sipping. Our research combine the characteristics of the energy efficiency with the shipbuilding industry with the novel and innovative design pattern which will be meaningful.
\end{abstract}

Keywords: Energy Efficiency; Ship Industry; Ship Design Process; Definition and Influence.

\section{Introduction}

In today's financial crisis spread, enterprise external management environment serious forced ships to think how to survive in the changing environment to keep and make a profit. The competition of shipyard is on the order, in addition to competitive price which cost and performance aspects include competition. Quality management leads to market the competition to the quality management of upsurges. Customer demand for personalized, different owners have their own demands, leading to each ship will have different places, how to keep good quality are the different demands of a project. Ship concept design phase, designers tend to be worked out according to the design plan descriptions of the initial displacement and form coefficient, due to the limited data provided, from the traditional approach of buoyancy people determine the displacement and principal dimensions and then to capacity, freeboard, stability, rapidity and maneuverability, seakeeping validation, check, etc. In the category of target cost management, will be reflected on the design drawings of the product cost called design costs, it is the formation of the products actual cost basis, and largely determines the actual cost of products [1]. Ship design target cost management is to make the design director and designer to attend the discussion of the ship design cost objectives and formulation, forming a system of target, and the implementation of the layers of decomposition, the ship design staff to make the goal and try to finish the work of self-control management methods.

Modern shipbuilding mode design method is different from the traditional shipbuilding mode, its design principles should be resolved in "how to build the ship" at the same time, also to solve "how to shipbuilding", is the "how to build the boat" and how to shipbuilding "be in harmony are an organic whole, therefore, ship design in production design, and put it as an important part of the ship design. Introduce the production design is not only the change of the ship design method, and embody the modern shipbuilding mode as an important symbol of change on the design. The characteristics of modern shipbuilding design could be separated into the follows parts. (1) Emphasizes the design must be in advance through the ready for the project 
management, including technical preparation, planning and engineering control preparation, prepared as the premise of design work, and in the design process to deal with the design phase of the close ties between mutual penetration, cross each other, make a design of advance preparation can be combined with each other in all stages of design throughout the ship design process. The basic design characteristics of modern shipbuilding, decided to the division of the design method in the design phase, the combination of design and engineering management and coordination of the design has its unique way. (2) It must be emphasized in the basic design process, the design of ship product as the final product, step by step according to their grade each manufacturing jobs. (3) Emphasized in the design process must be prepared to the combination of design, technology, management, use the advanced shipbuilding technology, by expanding the pre-outfitting, the overall optimization under the premise of "how to shipbuilding", by the various departments mutually agreed, put forward the reasonable requirements from the point of view of project management, finally in the form of design diagram "how to shipbuilding" embodied in the work and the management on the diagram as the basis of site construction guidance. In the figure one, we visually demonstrate the modern shipbuilding design.

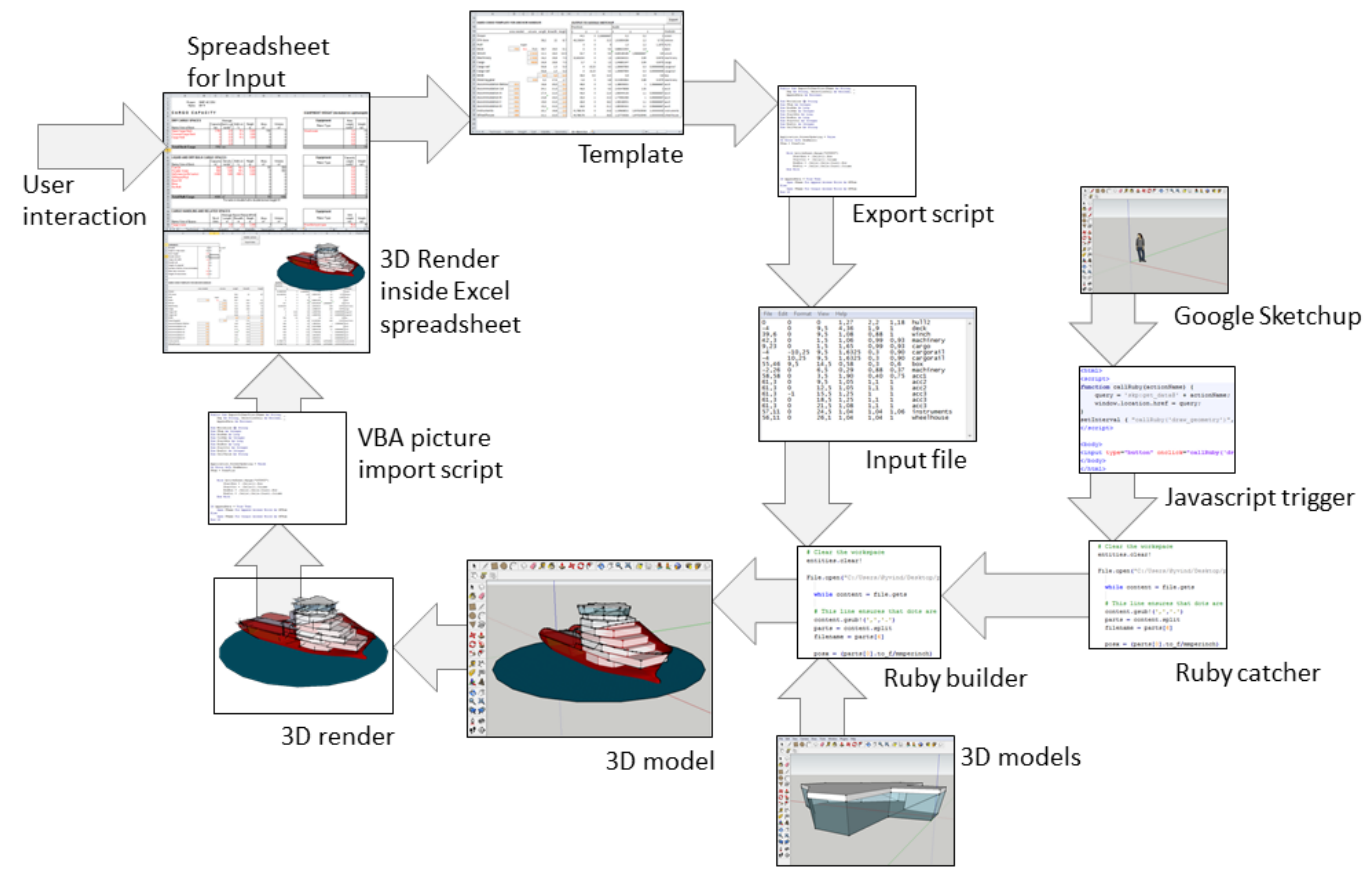

Figure 1.The Characteristics Demonstration of the Modern Shipbuilding Design

In this paper, we conduct research on the definition and influence of new production of ship industry index of energy efficiency on the ship design process. Ship design has a decisive influence on ship's technical and economic performance, in content is very complex, needs to solve many technical and economic contradictions, many contradictions embodies the ship design is a need to constantly make the decision of the multi-criteria decision-making process. What say normally in ship design, grasp the main contradiction, the design method of the essentially a method according to the designers prefer to make decisions. The detailed introduction will be conducted in the next sections. 


\section{The Proposed Perspective and Methodology}

The Design of Energy Efficiency Index of the

Ship. Ship energy saving is the key to energy saving ship form optimization design. In the ship under the conditions of use, and to optimize the design of the hull lines with boat, minimize the ship resistance, with a choice of ship host fuel-sipping, make overall harmonious match, the ship, in order to achieve the best configuration of machine, propeller and rudder to improve efficiency of ship propulsion, reduce operating costs. The following three equations illustrate the three essential parts of the energy efficiency index of the ship.

$$
f_{1}=\left(\prod_{j=1}^{M} f_{i}\right)\left(\sum_{i=1}^{n M E} P_{M E(i)} C_{F M E(i)} S F C_{M E(i)}\right)
$$

In ship design in the past, usually for static water speed, and actually ships mainly sailing in the waves, and even to perform operational tasks under the severe sea condition. Resistance is increased, but at slow speeds under ship operating at a high speed in the process, so the development of this type has achieved excellent. To develop a small water-plane area twin hull can adapt to sailing in waves, and the small resistance. This kind of ship hull is composed of on, to uncover her nakedness, mainly the upper hull, to uncover her nakedness is complementary hull, connected by a pillar, will be for the most part main hull volume carried out of the water. The following formula two expresses the feature.

$$
f_{2}=\left(\left(\prod_{j=1}^{M} f_{i} \sum_{i=1}^{n P T I} P_{n P T I}-\sum_{i=1}^{n e f f} f_{\text {neff }(i)} P_{A E E e f f(i)}\right) \times C_{F A E} S F C_{A E}\right)
$$

In terms of improving burning diesel fuel, researchers has successfully developed new turbo technology, by using a two-stage turbocharger to increase pressure, increase the amount of air in the cylinder, the fuel burn more fully, in improving the engine output power and power density at the same time, significantly reduce harmful gas emissions [2]. The following equation defines the feature.

$$
f_{3}=\left(\sum_{i}^{\text {neff }} f_{\text {eff }(i)} P_{\text {eff }(i)} C_{F M E} S F C_{M E}\right)
$$

Fuel quality is a key factor affecting the energy consumption, low price but poor quality fuel oil, not only to bring the work of diesel engine fault, and due to its poor combustion, may to a certain extent, also cannot achieve the purpose of cost reduction, it may actually increase fuel consumption, increase the maintenance cost and do more harm than good. Host this situation for basic use heavy fuel oil, by using fuel homogenizer for processing as one of the main means is to improve the combustion effect. The principle of which is through mechanical cutting, grinding and stick together in the heavy oil molecules apart, large oil particles become smaller, so that the fuel oil viscosity is greatly reduced, the oil is more uniform, greatly improved the quality of fuel, more conducive to the full combustion of fuel, improve combustion efficiency. Due to the improvement of combustion, effectively reduce the phenomenon of coking chamber, carbon and slows the wear of piston ring and cylinder liner, the save spare parts at the same time, the workload of the diesel engine maintenance. At the same time, because the oil particles small, uniform, and to reduce the self-cleaning filter washing times and slag discharge capacity and reduce the fuel consumption caused by slag discharge.

The modification and optimization work could be generally separated into the following parts. (1) Oar rotates freely after booster impeller. Electronic timing cyclone spray type cylinder oil lubrication system, changed the former cylinder oil adopts mechanical timing oil and lubrication of piston ring cloth traditional lubrication method, and use of electronic timing oil, improve the oil pressure, is advantageous to the oil atomization, combining rotating scavenging air dispersed oil lubrication, reduces the cylinder oil consumption, decrease of cylinder liner wear. (2) The rudder 
with thrust fin. Rudder thrust fin attached is a new kind of energy recycling slipstream of energy-saving device, its action principle is to make the water after a certain angle of attack of fixed fins change the direction of the original to increase the thrust, the results show that the rudder with thrust fin wake in the recycling field is part of the rotational energy to generate additional thrust. (3) LIPS efficient rudder. Lips efficient rudder can also be called oar rudder integration device. In the middle of the blade part, extending along the propeller shaft axis direction, welding with a streamlined spindle shape of rudder ball model test confirmed that compared with conventional rudder, after effectively with rudder propulsion power and can effectively reduce the fuel consumption [3].

The Core Techniques of Ship Design. Modern shipbuilding mode of design, because must carry out the design principle of the design, production, management integration and design to prepare in advance and design principles of each design phase combination must be taken to design and engineering management combined with the design of the way. The general steps and procedures of designing could be summarized as the follows. (1) The modern ship design production technical preparation stage. In essence belongs to simulate shipbuilding production technical preparation stage. From management point of view in the correct management thought as guidance, through the early planning of project management, overall coordination; At the same time, and with the right design thought, the system design and regional design on the figure simulation integrated shipbuilding. (2) Deciding on a policy to build. Method was built to take order early, in understanding the order of the ship main technical parameters, structure, main equipment, the overall layout, on the basis of the new ship to make a rough block division, determine the preliminary schedule of construction method, construction principles and major nodes arrangement, in order to estimate of the production cycle have altogether to build policy is the core of the construction program, after the contract signing, in the preliminary design and detailed design stage. (3) Given operating procedures. The job order is the further refine the construction main point, especially for key job of the new shipbuilding, operating procedures must be identified. It corresponds to the production design stage is proposed, and to guide the production design. It is based on the hull, outfitting, painting as the key point, advanced modern shipbuilding technology as the leading factor, and through the process, schedule, cost, quality, construction and so on comprehensive balance the construction of the proposed optimization scheme, both as a new comprehensive technical documents of the ship, guides the work of each department, and as a guide the detailed design and subsequent design phase of the program.

The Influence and Prospect of New Production of Ship Industry. The shipping enterprise's competition is related to a country's economic strength developed countries in the world are guided by the sea, the sea strategy. Our country is a maritime power, the size of the ship. Because has put into the supplementary provisions will enforce legal framework. So shipping companies to establish ship energy efficiency management system is imminent. Shipping companies and related units can make use of the energy efficiency management system, improving energy efficiency to reduce greenhouse gas emissions. This will help shipping companies in the management efficiency, to improve emissions and reduce the energy consumption, increase energy efficiency, good effect. However, our country has not formulated the corresponding standards of energy efficiency of the ship. The statistical index of ship energy performance has not been unified. So domestic shipping industry need to establish a series of statistical methods, analysis system. Formulate relevant laws and regulations, and rules to escort for the reasonable 
development of green shipbuilding and shipping industry.

Energy efficient standard puts forward higher requirements on the shipbuilding industry. The essence of the technical measures to reduce emissions which is to improve the ship energy efficiency, the shipbuilding industry of our country and related supporting industries of science and technology innovation put forward higher and newer requirements. At present, China's shipbuilding industry is in a critical period of transition which should seize the opportunity to increase investment in research and development, reform and innovation mechanism, change the pattern of economic growth, to master core technologies and key technologies of shipbuilding. Energy conservation and emissions reduction measures impact on shipping market. Rise in the cost of shipbuilding, ship investment purchases or modification of the ship operating cost increases. In addition, the use of shore power, pay a carbon tax and other measures will increase the ship's operating burden. Operating costs will eventually be passed on to the owner and the rate of increase will weaken the competitiveness of ship relative to other alternative modes and patterns of transportation.

\section{Conclusion}

In this paper, we conduct research on the definition and influence of new production of ship industry index of energy efficiency on the ship design process. With fuel prices rising, the cost of shipping company is becoming more and more big, the demand for ship energy saving is becoming more and more high, all kinds of propulsion performance is good, save fuel ship will be more widely popular, and overall design, loading optimization, ship equipment using aspects pay more attention to the application of new energy saving technology. Our research proposed novel paradigm of the industry which will help enhance the core competiveness of the Chinese ship industry.

\section{References}

[1] Papanikolaou, Apostolos, Alfred Mohammed, E, Hirdaris, Spyros E. Stochastic uncertainty modelling for ship design loads and operational guidance[J]. Ocean Engineering, 2014, 86(8).

[2] Liang C, Chen X. Support of the Ship Design Process Model in Collaborative Design[J]. Science \& Technology \& Innovation, 2015.

[3] Jones, Adam T. Design space exploration and optimization using modern ship design tools[J]. Massachusetts Institute of Technology, 